\section{The Canadian Association of Gastroenterology ePortal - launched September 2009}

\author{
Alaa Rostom MD FRCPC MSc, Chair, CAG Education Committee \\ University of Calgary, Calgary, Alberta
}

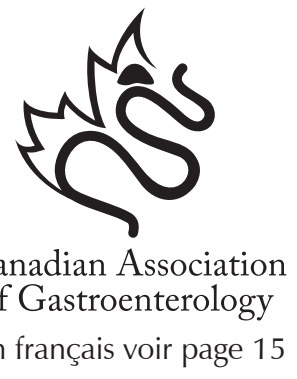

Canadian Association
of Gastroenterology
En français voir page 15

the Web site at www.cag-acg.org. A login and password is required to use the ePortal (it is the same as your login for the members page of the CAG Web site). If you cannot remember your login information, you can contact the CAG office or use the 'Forgot your password?' utility on the members page of the CAG Web site. The system will allow members to perform personal needs assessments and create a personal profile to target areas of interest.

What's on the ePortal?

The ePortal includes a variety of learning and educational programs such as:

- Video lectures with pre- and post-test questions;

- Video lectures;

- Discussion forums;

- Endoscopy quiz; and

- Resources (eg, clinical practice guidelines, position papers).

Why use the ePortal?

- Centralize your educational activities and records;

- Use a large variety of tools available on the CAG ePortal;

- Earn credits to meet your maintenance of certification learning needs while having these credits automatically logged to your personal ePortal profile;

- Review lectures from previous meetings that you have not been able to attend;

- Join interactive discussion forums to chat with the experts;

- Create and perform self-assessment programs easily;

- Access key resource materials such as clinical practice guidelines and position papers.

Visit www.cag-acg.org often for updates regarding this opportunity and to access the many other benefits available to members!

The CAG ePortal is the gateway to CAG members' on-line continuing professional development learning opportunities. Members are able to access the ePortal at their leisure through

The CAG is proud to acknowledge its Benefactor Corporate Sponsors:

Abbott Canada
Axcan Pharma Inc

Olympus Canada Inc 


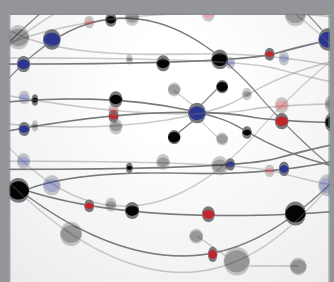

The Scientific World Journal
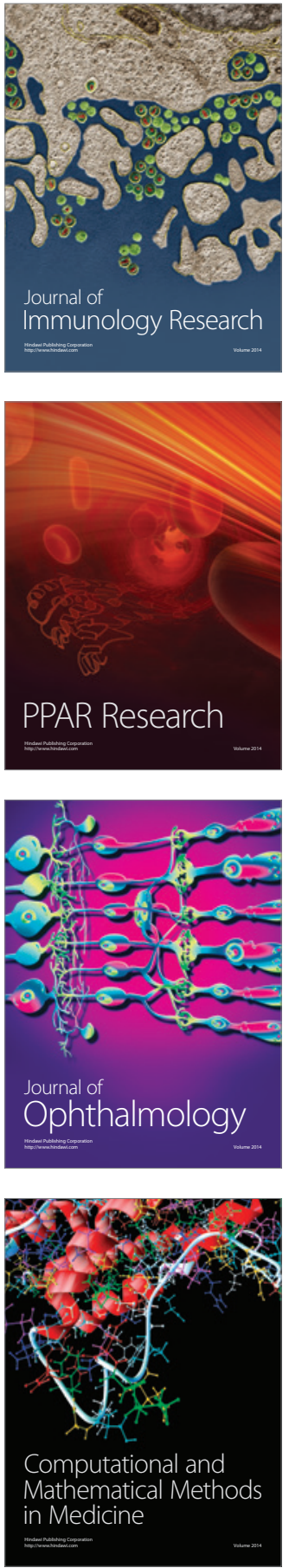

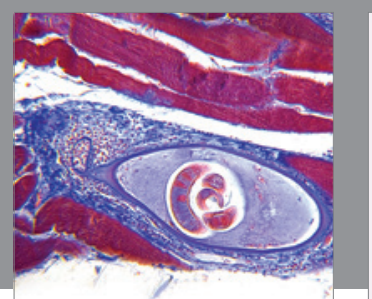

Gastroenterology Research and Practice

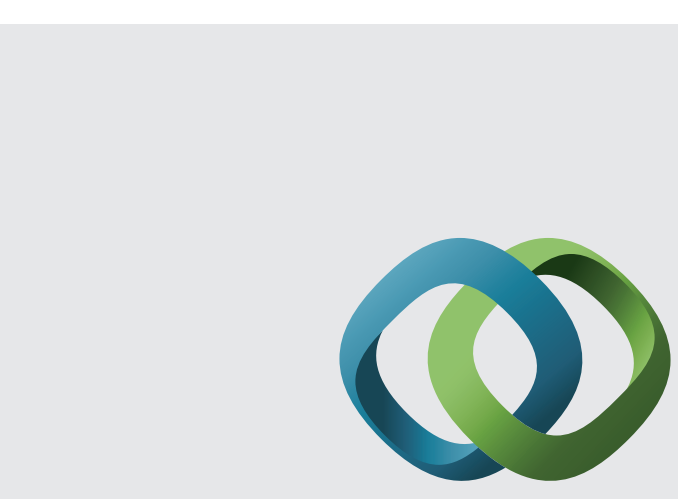

\section{Hindawi}

Submit your manuscripts at

http://www.hindawi.com
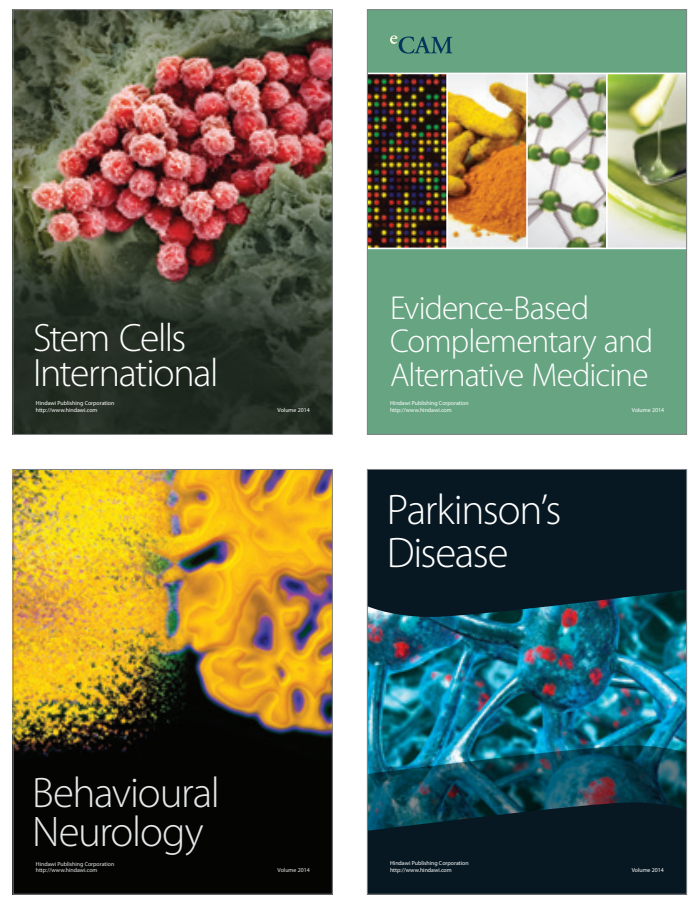
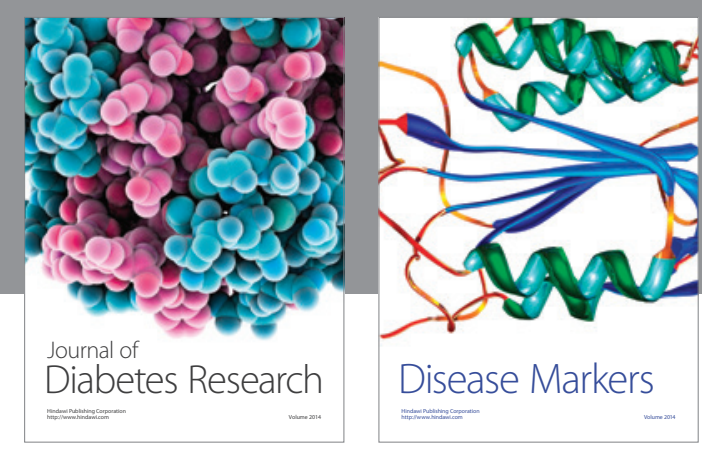

Disease Markers
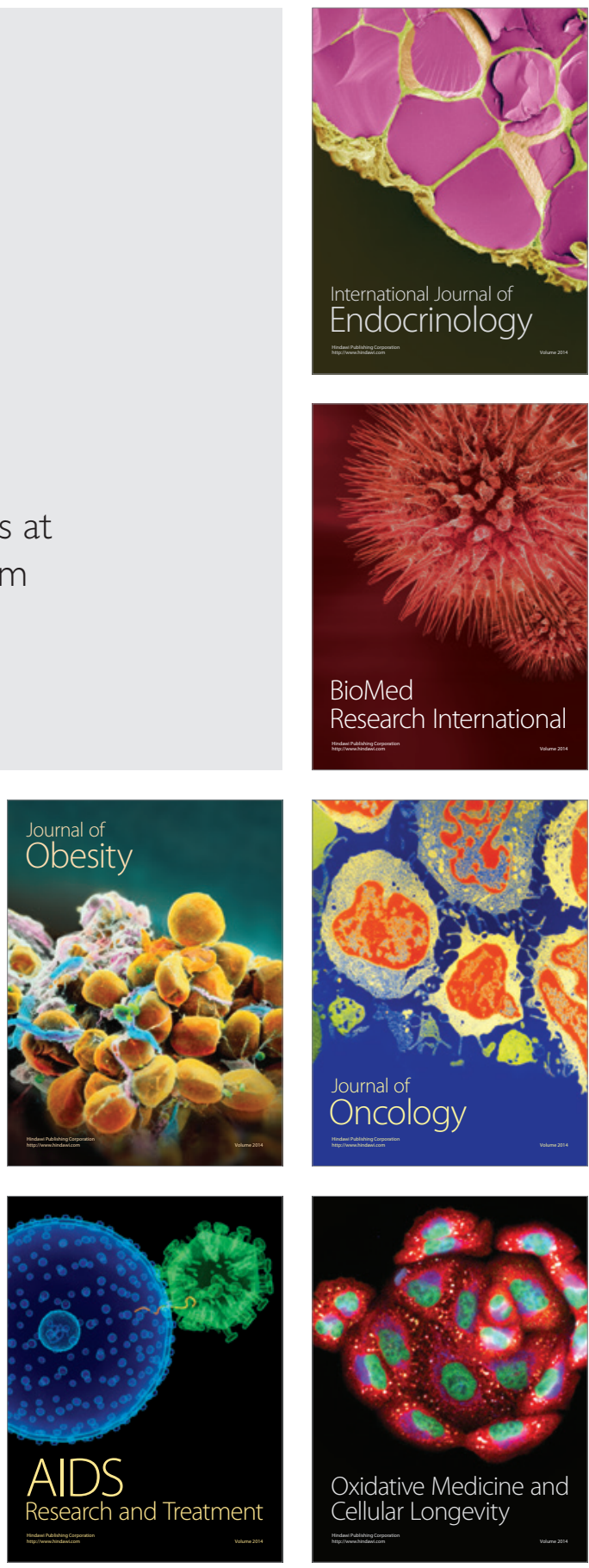